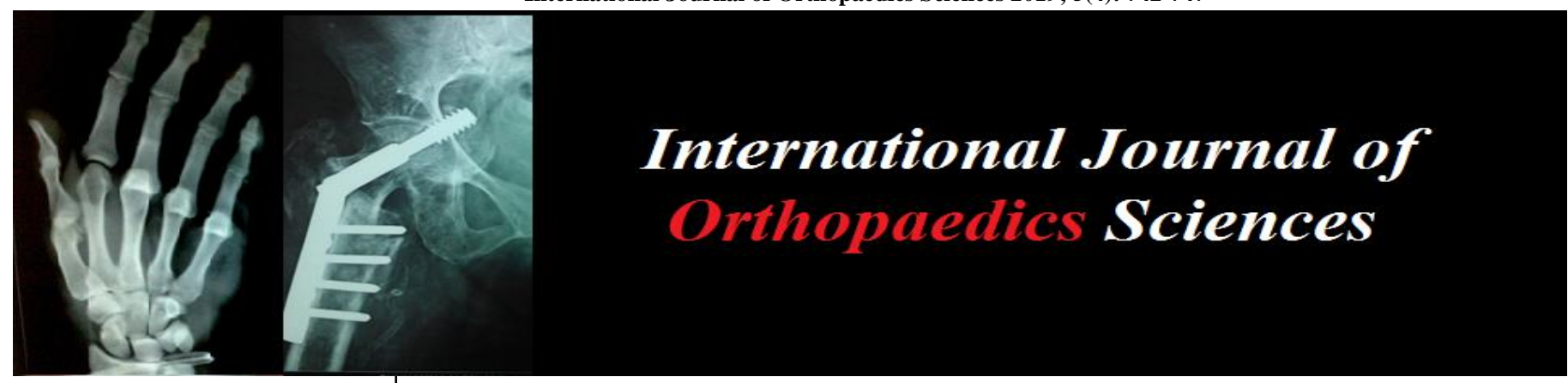

E-ISSN: 2395-1958

P-ISSN: 2706-6630

IJOS 2019; 5(4): 742-747

(C) 2019 IJOS

www.orthopaper.com

Received: 09-08-2019

Accepted: 13-09-2019

Sunil Manual

Associate Professor, Department of Orthopedics, SDM Medical

College and Hospital, Dharwad,

Karnataka, India

Shrihari LK

Associate Professor, Department of Orthopedics, SDM Medical

College and Hospital, Dharwad,

Karnataka, India

H Shatanand Prasad Rao Jr Resident, Department of Orthopedics, SDM Medical

College and Hospital, Dharwad, Karnataka, India

Manjunath S Daragad

Professor, Department of

Orthopedics SDM Medical

College and Hospital, Dharwad,

Karnataka, India
Corresponding Author:

Shrihari LK

Associate Professor, Department of Orthopedics, SDM Medical

College and Hospital, Dharwad,

Karnataka, India

\section{Surgical management of diaphyseal fractures of the humerus with plate osteosynthesis on anteromedial surface}

\author{
Sunil Manual, Shrihari LK, H Shatanand Prasad Rao and Manjunath S \\ Daragad
}

DOI: https://doi.org/10.22271/ortho.2019.v5.i4m.1762

\section{Abstract}

Background: Humeral shaft fractures represent approximately 1-5 \% of all fractures. Non-operative management of humeral shaft fractures is the mainstay of treatment with some drawbacks. The surgical options for a closed humerus diaphyseal fracture are plate osteosynthesis and intramedullary nailing, the previous being gold standard for last four decades. The aim of this study is to evaluate the union rates and functional outcome of anteromedial plate fixation in diaphyseal fractures of the humerus.

Materials and Methods: 56 patients treated in a tertiary care medical teaching hospital between June 2015 and May 2019 were enrolled in the study. The humerus was approached by Henry`s approach, fractures were reduced and fixed with $4.5 \mathrm{~mm}$ narrow DCP or LCP on the anteromedial surface. All patients were followed up for minimum of 6 months. Modified Stewart and Hundley scoring was used to grade the outcome.

Results: Out of 56 patients 41 were males and 15 females, with mean age of 36.5 years. Road traffic accidents were the most common mechanism of injury. The most common fracture pattern was A3 followed by A2. The average time taken for fracture union was 13.8 weeks. 44 patients had excellent to good functional outcome. Three patients had delayed union and one had non-union. None of the patients had iatrogenic radial nerve injury.

Conclusion: Plating on anteromedial surface using an anterolateral approach is very good technique for management of humerus shaft fractures with good functional outcome and lesser incidence of radial nerve injury.

Keywords: Humerus shaft fractures, anteromedial surface, modified stewart and hundley scoring

\section{Introduction}

Humeral shaft fractures represent approximately 1-5 \% of all fractures. The humeral shaft extends between the upper borders of the insertion of the pectoralis major muscle proximally to the supracondylar ridge distally ${ }^{[1]}$. There is a bimodal distribution of this fracture with peaks primarily in young patients and a larger peak in elderly women.

Structurally, the humerus is cylindrical proximally which provides strength and resistance to both torsional and bending forces and tapers distally to a triangular shape. It is enveloped in a thick muscle and soft tissue covering leading to rapid healing due to the high vascularity. Because the glenohumeral joint has an exceptional range of motion in many planes, deformity is well tolerated after union. Acceptable fracture alignment includes 20 degrees of anterior bowing, 30 degrees of varus angulation, 15 degrees of malrotation, and $3 \mathrm{~cm}$ of shortening ${ }^{[2]}$. The large muscle mass surrounding the humerus conceals deformity in the skeletal structure itself. Additionally, since the humerus is not involved in weight-bearing, no functional disability results if there is shortening.

Traditionally, non-operative management of humeral shaft fractures is the mainstay of treatment although there can be some drawbacks ${ }^{[3]}$. With the advent of new surgical techniques and implant options there is less tolerance for acceptable deformity and functional deficits on part of the patients and treating physicians ${ }^{[4]}$. The surgical options for a closed humerus diaphyseal fracture are plate osteosynthesis and intramedullary nailing ${ }^{[5]}$. 
Since the humerus is a long bone subject to significant rotational forces, plate osteosynthesis with multiple points of contact in the bone is considered superior to intramedullary nailing. Dynamic compression plates (DCP) have been the mainstay of treatment since the last four decades. Over the last decade Limited Contact Dynamic Compression Plates (LC-DCP) with minimal contact points on the bone leading to lesser compression of periosteal blood supply has largely replaced the use of DCPs ${ }^{[6]}$.

Surgical approaches to plate fixation of humeral shaft are dictated by the location of the fracture. The anterolateral exposure utilizing the deltopectoral interval with extension down the arm through a brachialis split provides excellent exposure to the proximal and middle third of the diaphysis. Distal extension is limited by the radial nerve piercing the lateral intermuscular septum [7]. The posterior approach facilitates exposure of distal third fractures of the humerus ${ }^{[8]}$. The standard method of plate osteosynthesis for fracture shaft humerus is with anterolateral plating or posterior plating. The lateral surface of the humerus is not a smooth surface unlike the medial surface. The lateral surface is gently curved with irregularities due to deltoid attachment. This leads to poor contact of the plate to the bone necessitating pre-bending of the plate. In the distal third-middle third junction of the humerus, the radial nerve passes from posterior to anterior as it pierces the lateral intermuscular septum. This can lead to radial nerve injury either by direct compression of the nerve by the plate or by inadvertently placed bone levers The incidence of radial nerve palsy through posterior approach is $11 \%$ and with anterolateral plating is $5.4 \%{ }^{[9]}$. In the present study, we have performed plate osteosynthesis on the anteromedial surface using an anterolateral approach which has the advantage of easy, reliable plate fixation due to the smooth surface on the medial side and reduced chances of injury to the radial nerve. The aim of this study is to evaluate the union rates and functional outcome of anteromedial plate fixation in diaphyseal fractures of the humerus.

\section{Materials and Methods}

The study is a prospective study of patients with closed diaphyseal fractures of the humerus treated in a tertiary care medical teaching hospital between June 2015 and May 2019. Patients above 16 years treated with anteromedial plate osteosynthesis through an anterolateral approach available for a final follow-up after 6 months were included in the study. Patients with open fractures, segmental fractures, pathological fractures, fractures with neuro-vascular injuries and associated injuries in the same limb were excluded from the study.

A total of 62 patients satisfying the inclusion criteria were enrolled in the study. 6 patients were lost for follow-up and were eliminated from the study thereby bringing the final count of the study patients down to 56. Relevant demographic data like age, sex, occupation, contact details and comorbidities were recorded in the study proforma. Additionally, injury related details like mode of injury, time since injury, side of injury, associated chest injury, health of the overlying soft-tissue sleeve, level of the fracture and classification of fracture as defined by AO/OTA were noted [10]. A written informed consent was obtained from all patients regarding the surgical management and the post-operative protocol. Patients were taken up for surgery under brachial block or general anaesthesia. The humerus shaft was approached by the standard Henry's approach [11]. The arm was externally rotated to facilitate the visualization of the anteromedial surface of the humerus. Fractures were reduced and fixed with $4.5 \mathrm{~mm}$ narrow DCP or LCP by the AO principle. Post-operatively, the arm was supported in an arm pouch and gentle range of movement exercises of the shoulder and elbow were started from the second postoperative day. Patients were discharged with arm pouch with advice to continue elbow flexion and pendulum exercises for shoulder joint. Sutures were removed between tenth and fourteenth day on out-patient basis. Patients were regularly followed up at 12 weeks, 3 months and 6 months. During each follow up functional recovery was assessed and the progress of fracture healing was radiologically documented. At a final follow-up of 6 months, Modified Stewart and Hundley Scoring was used to grade the outcome as excellent, good, satisfactory and poor ${ }^{[12]}$.

Table 1: Modified Stewart and Hundley Scoring ${ }^{[12]}$

\begin{tabular}{|c|c|}
\hline Outcome & Parameters \\
\hline Excellent & $\begin{array}{c}\text { Bony union } \\
\text { Lack of pain } \\
\text { Full mobility of adjoining joints }\end{array}$ \\
\hline Good & $\begin{array}{c}\text { Union } \\
\text { Slight pain } \\
\text { Limitation of mobility of adjoining joints less than } 20 \text { degrees } \\
\text { Angular positioning of bone less than } 10 \text { degrees }\end{array}$ \\
\hline Satisfactory & $\begin{array}{c}\text { Union } \\
\text { Periodical pain } \\
\text { Limitation of mobility of adjoining joints between } 20 \text { and } 40 \text { degrees } \\
\text { Angular positioning }>10 \text { degrees }\end{array}$ \\
\hline Poor & $\begin{array}{c}\text { Lack of union } \\
\text { Pathological mobility } \\
\text { Continuous pain } \\
\text { Limitation of adjoining joints }>40 \text { degrees } \\
\text { Nerve injury }\end{array}$ \\
\hline
\end{tabular}

\section{Results}

A total of 56 patients satisfying the inclusion criteria were included in the final analysis. The age group of patients in our study ranged from 16 to 67 years (mean age: 36.5 years). There were 41 males $(73.2 \%)$ and 15 females (26.7\%). Road traffic accidents were the most common mechanism of injury accounting for $40(71.4 \%)$ patients followed by fall from height in $9(16 \%)$ patients. Work place injuries, sports injuries and assault accounted for the rest of the patients. $30(53.5 \%)$ patients had injury to left humerus. The most common fracture pattern noted in our study was A3 type followed by A2 type according to AO classification. Chest injury (15 
patients) was the most common associated injury in the patients with humerus shaft fractures, followed by head injury
(12 patients).

Table 2: Demographic details

\begin{tabular}{|c|c|c|c|}
\hline \multicolumn{2}{|c|}{ Demographic variation } & Number & Percentage \\
\hline \multirow{7}{*}{ Age } & $16-20$ & 4 & 7.1 \\
\hline & $21-30$ & 23 & 41 \\
\hline & $31-40$ & 12 & 21.4 \\
\hline & $41-50$ & 5 & 8.9 \\
\hline & $51-60$ & 7 & 12.5 \\
\hline & $61-70$ & 5 & 8.9 \\
\hline & Total & 56 & 100 \\
\hline \multirow{3}{*}{ Sex } & Male & 41 & 73.2 \\
\hline & Female & 15 & 26.7 \\
\hline & Total & 56 & 100 \\
\hline \multirow{3}{*}{ Side } & Right & 26 & 46.4 \\
\hline & Left & 30 & 53.5 \\
\hline & Total & 56 & 100 \\
\hline \multirow{4}{*}{ Mode of injury } & RTA & 40 & 71.4 \\
\hline & Fall from height & 9 & 16 \\
\hline & Others & 7 & 12.5 \\
\hline & Total & 56 & 100 \\
\hline \multirow{10}{*}{ AO/OTA Type } & A1 & 0 & 0 \\
\hline & $\mathrm{A} 2$ & 13 & 23.2 \\
\hline & A3 & 21 & 37.5 \\
\hline & B1 & 3 & 5.3 \\
\hline & B2 & 10 & 17.8 \\
\hline & B3 & 7 & 12.5 \\
\hline & $\mathrm{C} 1$ & 0 & 0 \\
\hline & $\mathrm{C} 2$ & 1 & 1.7 \\
\hline & $\mathrm{C} 3$ & 1 & 1.7 \\
\hline & Total & 56 & 100 \\
\hline
\end{tabular}

The average time taken for fracture union was 13.8 weeks (range 10-22 weeks). Three patients had delayed union and one patient had non-union. Three patients had superficial wound infection which required extended intravenous antibiotics. None of them required wound debridement and none of them had deep infection. None of the patients had iatrogenic radial nerve injury. Functional assessment at 6 months using Modified Stewart and Hundley scoring showed $44(78.5 \%)$ patients had excellent to good results, $10(17.8 \%)$ patients had satisfactory results and $2(3.5 \%)$ patients had poor functional outcome.

Table 3: Time to fracture union

\begin{tabular}{|c|c|c|}
\hline Time in weeks & Number of patients & Percentage \\
\hline$<10$ & 25 & 44.6 \\
\hline $10-20$ & 27 & 48.2 \\
\hline$>20$ & 3 & 5.3 \\
\hline Non union & 1 & 1.8 \\
\hline Total & 56 & 100 \\
\hline
\end{tabular}

Table 4: Function result by modified stewart and hundley scoring

\begin{tabular}{|c|c|c|}
\hline Functional result & Number & Percentage \\
\hline Excellent & 30 & 53.5 \\
\hline Good & 14 & 25 \\
\hline Satisfactory & 10 & 17.8 \\
\hline Poor & 02 & 3.5 \\
\hline Total & 56 & 100 \\
\hline
\end{tabular}

\section{Discussion}

Fractures of the humeral shaft account for roughly 1-5\% of all fractures and most can be treated non-operatively. Sarmiento and colleagues have published a relatively large series of 620 patients with $97 \%$ union rates and high satisfaction rates with functional bracing. They demonstrated the benefits of treatment with functional bracing as it leads to acceptable outcomes with little morbidity ${ }^{[3]}$. These excellent results have not however been consistently reproduced in other studies, which is why there continues to be controversy regarding optimal management. Rutgers and Ring retrospectively found that proximal-third long oblique fractures may be at greater risk of nonunion due to the pull of the deltoid on the distal aspect of the proximal fragment and muscle interposition as are transverse, displaced fractures of the middle and distal thirds of the humeral shaft ${ }^{[13]}$. Wallny et al found that the ideal indication for functional bracing of the humeral shaft is in spiral or oblique fractures of the middle or proximal third of the humerus, and they did not recommend bracing for distal humerus fractures ${ }^{[14]}$. The surgical management in the form of plating and nailing has become the standard treatment of choice for the patients with humerus shaft fractures for early mobilization in last two to three decades ${ }^{[15]}$. Denies in his study compared conventional plating with intramedullary interlocking nail in 91 patients. He reported high complication rate with intramedullary nail and suggested plating as primary treatment for humeral shaft fractures ${ }^{[16]}$.

Anterolateral and posterior plating are commonly used as treatment option for the fracture shaft of the humerus, plating on anteromedial surface has not been commonly reported. ${ }^{9}$ According to the tension band principle, the lateral and posterior surfaces of the humerus are the tensile surface where plate should ideally be placed. The stresses on humerus however are more of rotational stresses as it is a non-weight bearing bone. Thus plating may also be done on the medial surface of the humerus ${ }^{[17]}$.

The placement of a plate on anterolateral surface of humerus 
carries potential damage to radial nerve either by traction injury by fracture reduction, compression by retractors or bone levers or by implant itself ${ }^{[18]}$. The anterolateral approach with placement of plate on anteromedial surface prevents the unnecessary dissection at lateral side of humerus and avoids injury to the radial nerve by the retractors and the implant ${ }^{[9]}$. Very often, placing a plate on the anterolateral surface of the humerus necessitates erasing a part of the deltoid attachment. This leads to limitation in shoulder abduction post-operatively. By placing a plate on the anteromedial surface, the deltoid attachment is well preserved. Plating on the anteromedial surface is also technically easy due to the flat medial surface which helps in achieving better contact of the plate to the bone.

In our study, the average time taken for fracture union was 13.8 weeks which is at par with most of the studies ${ }^{[19]}$. The final functional result achieved by anteromedial plating in our study is comparable with most standard studies ${ }^{[15]}$. From our results and surgical experience with anteromedial plating we are able to conclude that the technique has no drawback as compared to anterolateral plating, rather, it has a few technical advantages as stated above. Of the two patients in our study who had poor results, one had a non-union and the other had stiffness of the shoulder and elbow. The non-union could be attributed to a technical error in which the fracture was fixed in distraction. The patient additionally was a smoker, unwilling to give up his habit. This complication could have been prevented by adhering to AO principles of fracture fixation, patient education and proper rehabilitation. The patient with stiffness of the shoulder and elbow had poor pain tolerance and was not able to comply with the physiotherapy regimen. There were no technical and implant problems with the surgery and the fracture went on to heal uneventfully.

The technique of anteromedial plating however is limited by the location of the fracture in the diaphysis of the humerus. In all cases our aim was to get atleast three screws (six cortex purchase) and preferably four screws (eight cortex purchase) on either side of the fracture. In some proximal and distal diaphyseal fractures when this was not possible we have to revert back to either the anterolateral approach or the posterior approach respectively to achieve stable fixation.

The medial approach to the humerus was first described by Judet in $1968^{[20]}$. The medial approach to the humeral shaft exposes the insertion of the pectoralis major muscle proximally down to the coronoid fossa distally [21]. This approach develops the interval between the biceps and triceps musculature, and requires exposure and protection of the ulnar nerve and brachial artery. This approach is usually reserved for tackling vascular injuries associated with humerus shaft fracture. Lu, et al described their study of medial plating in 18 patients using a medial approach citing the advantage of a well hidden scar. They also concluded that this approach was not suitable for proximal and distal diaphyseal fractures ${ }^{[17]}$. We have no experience with the medial approach and are comfortable using the anterolateral approach.

The limitation of our study is the limited number of patients and the short duration of follow-up.
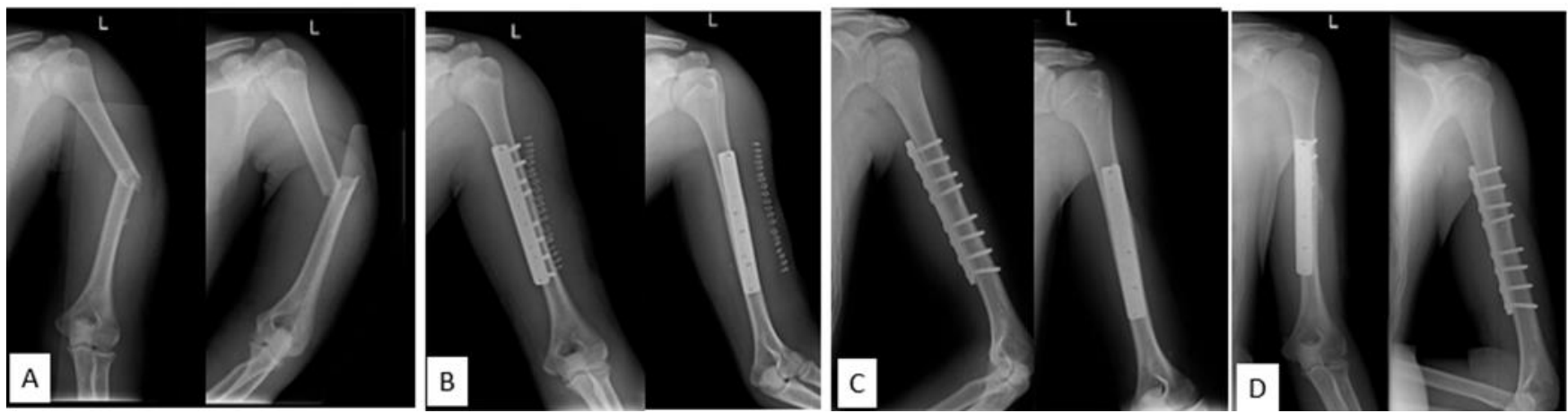

Fig 1: (A) Radiograph showing fracture middle third shaft of humerus at presentation. (B) Immediate post- operative radiograph. (C) Radiograph at 6 weeks. (D) Radiograph at 12 weeks post-surgery showing fracture union.
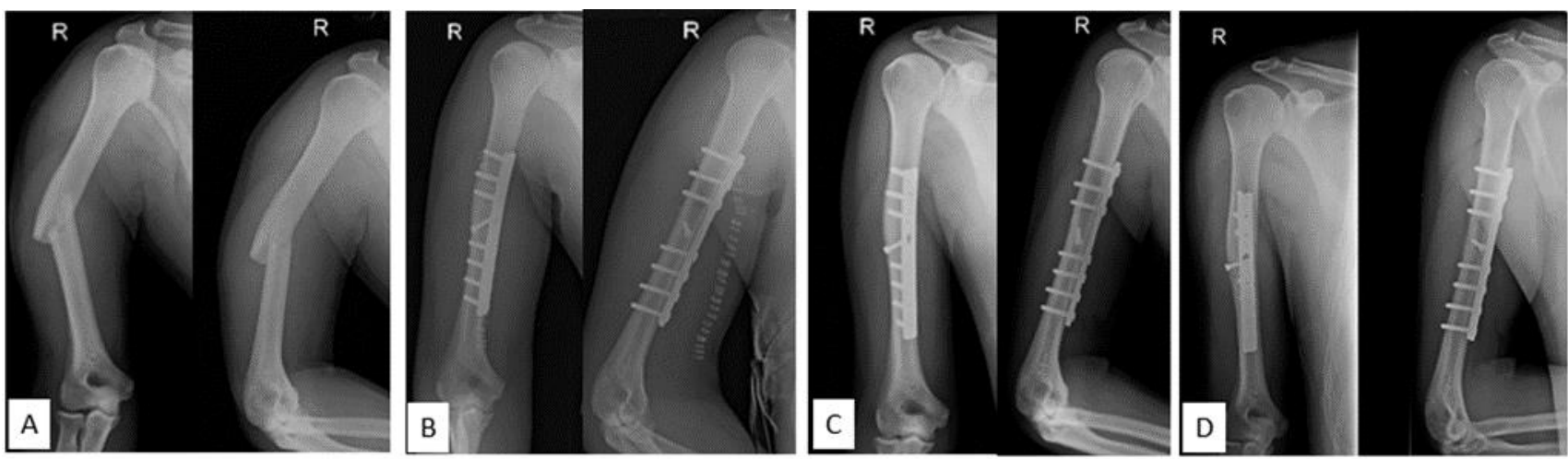

Fig 2: (A) Radiograph showing fracture middle third shaft of humerus at presentation. (B) Immediate post- operative radiograph. (C) Radiograph at 6 weeks. (D) Radiograph at 12 weeks post-surgery showing fracture union. 

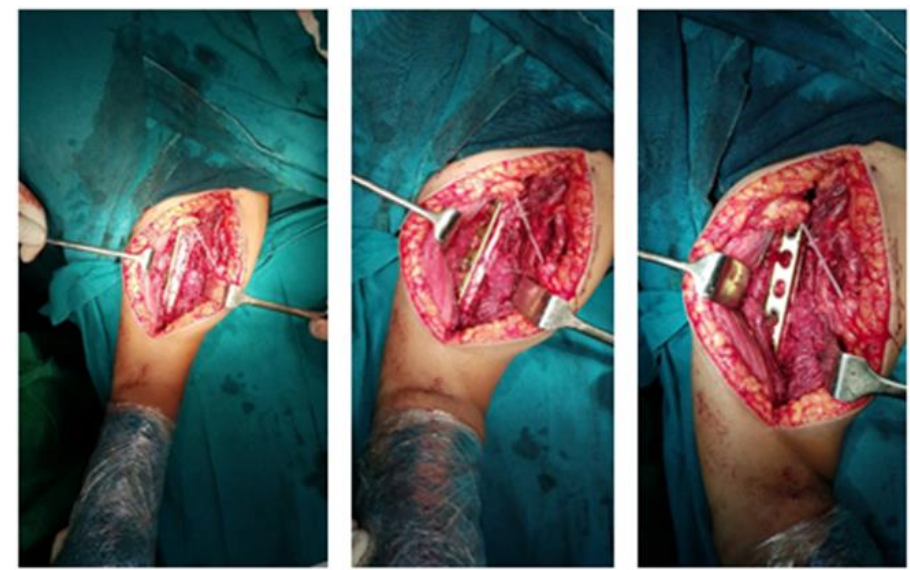

Fig 3: Intra operative pictures of fixation of humerus shaft fracture with plating on anteromedial surface using anterolateral approach
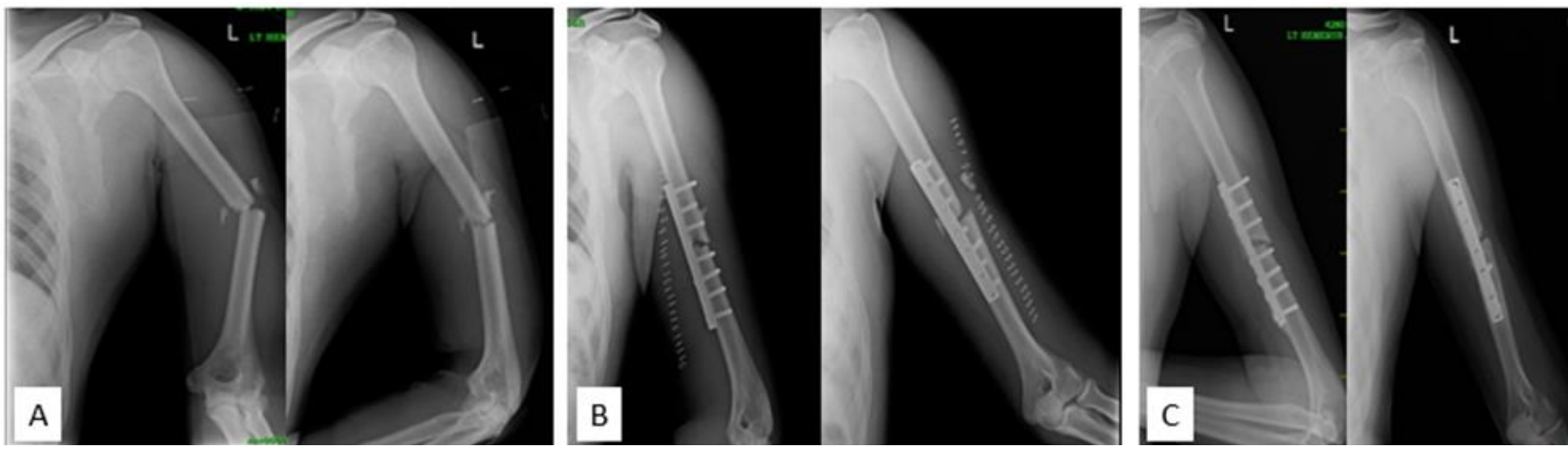

Fig 4: (A) Fracture of mid-shaft humerus. (B) Immediate post-operative radiograph. (C) Radiograph at one year follow-up showing non-union

\section{Conclusion}

Our study concludes that anteromedial plating through an anterolateral approach is a simple alternate technique for management of humerus shaft fractures with good fracture healing due to minimal soft tissue dissection, excellent functional result and lesser incidence of radial nerve injury.

\section{Conflict of interest}

Nil

\section{References}

1. Tytherleigh-Strong G, Walls N, McQueen MM. The epidemiology of humeral shaft fractures. The Journal of bone and joint surgery. British volume. 1998; 80(2):24953.

2. Klenerman L. Fractures of the shaft of the humerus. J Bone Joint Surg Br. 1966; 48:105-11.

3. Sarmiento A, Zagorski JB, Zych G. Functional bracing for the treatment of fractures of the humeral diaphysis. J Bone and Joint Surg Am. 2000; 82:478-86.

4. McCormack RG, Brien D, Buckley RE, McKee MD, Powell J, Schemitsch EH. Fixation of fractures of the shaft of the humerus by dynamic compression plate or intramedullary nail. A prospective, randomized trial. J Bone Joint Surg Br. 2000; 82(3):336-339.

5. Chapman JR, Henley MB, Agel J, Benca PJ. Randomized prospective study of humeral shaft fracture fixation: intramedullary nails versus plates. J Orthop Trauma. 2000; 14:162-6.

6. Sarmiento A, Waddell JP, Latta LL. Diaphyseal humeral fractures: treatment options. JBJS. 2001; 83(10):1566-79.

7. Mills WJ, Hanel DP, Smith DG. Lateral approach to the humeral shaft: an alternative approach for fracture treatment. J Orthop Trauma. 1996; 10:81-6.

8. Zlotolow DA, Catalano 3rd LW, Barron OA, et al.
Surgical exposures of the humerus. J Am Acad Orthop Surg. 2006; 14:754-65.

9. Kirin I, Jurišić D, Grebić D, Nadalin S. The advantages of humeral anteromedial plate osteosynthesis in the middle third shaft fractures. Wiener klinische Wochenschrift. 2011; 123(3-4):83-7.

10. Creevey W, De Coster TA, Prokuski L, Sirkin MS, Ziran $\mathrm{B}$, Henley B, et al. Fracture and dislocation classification compendium. J Orthop Trauma. 2007; 21(10):S1-33.

11. The Humerus. In: Surgical exposures in Orthopaedics: The Anatomic Approach, Hoppenfeld S, deBoer P, Buckley R (Eds). Philadelphia: Lippincot Williams \& Wilkins; 4th ed. 2009, p.146-178.

12. Stewart MJ, Hundley JM. Fractures of the humerus; a comparative study in methods of treatment. J Bone Joint Surg Am. 1955; 37-A(4):681-92.

13. Rutgers M, Ring D. Treatment of diaphyseal fractures of the humerus using a functional brace. J Orthop Trauma. 2006; 20:597-601.

14. Wallny T, Westermann K, Sagebiel C. Functional treatment of humeral shaft fractures: indications and results. J Orthop Trauma. 1997; 11:283-287.

15. Cole PA, Wijdicks CA. The operative treatment of diaphyseal humeral shaft fractures. Hand Clin. 2007; 23:437-48

16. Denies E, Nijs S, Sermon A, Broos P. Operative Treatment of Humeral Shaft Fractures. Comparison of Plating and Intramedullary Nailing. Acta Orthopaedica Belgica. 2010; 76:735-742.

17. Lu S, Wu J, Xu S, Fu B, Dong J, Yang Y, et al. Medial approach to treat humeral mid-shaft fractures: A retrospective study. J Orthop Surg Res. 2016; 11:32.

18. Böstman O, Bakalim G, Vainionpää S, Wilppula E, Pätiälä $\mathrm{H}$, Rokkanen $\mathrm{P}$. Immediate radial nerve palsy complicating fracture of the shaft of the humerus: when is 
early exploration justified? Injury. 1985; 16(7):499-501.

19. Klenerman L. Injuries of the arm. 6th ed. In: WatsonJones Fractures and joint injuries, Wilson FN (ed). New Delhi: Churchill Livingstone. 1992. p.572.

20. Judet R, Patel A, Demeulenaere C. 3 approaches to the upper part of the humerus and the humeral diaphysis. Presse Med. 1968; 76(41):1961-3.

21. Jupiter J. Complex non-union of the humeral diaphysis. Treatment with a medial approach, an anterior plate, and a vascularized fibular graft. J Bone Joint Surg Am. 1990; 72:701-7. 